\title{
A computational model for cell energy balance and metabolism
}

\section{Mehrshad Sadria}

Anita T. Layton

\section{Video Byte}

Keywords: ageing, autophagy, growth factor signaling, metabolism, proliferation, mTOR, NAD+, longevity, sirtuins, system biology, Cell Communication and Signaling

Posted Date: October 13th, 2021

DOI: https://doi.org/10.21203/rs.3.rs-967549/v1

License: (c) (i) This work is licensed under a Creative Commons Attribution 4.0 International License. Read Full License 


\section{Abstract}

Survival is a complex energy-balancing act that involves a number of cell signaling pathways. One important player in this act is the protein mTORC1. Previous studies have shown that inhibiting mTORC1 is beneficial for health-and lifespan-serving as one promising way to fight cancer, for example. Now, a new computational model could reveal important details about key players in aging. This model captures the dynamic of known key players in the aging process, such as AMPK, mTORC1, and SIRT signaling pathways. Model simulations indicated that PRAS40 can be considered as another mTORC1 inhibitor. This access point is clinically important, as it provides a way of suppressing mTORC1 with the optimum dose of the inhibitor rapamycin, which at high doses and long exposure is known to cause problems such as insulin resistance. Results suggest that Sestrin2 is another potential candidate that can inhibit mTORC1. Additionally, findings showed that high doses of resveratrol or NAD can cause premature autophagy hyperactivation of SIRT1, an enzyme implicated in age-associated diseases. These and other findings suggest that the computational model could be used to inform new therapies against agingrelated diseases. 